\title{
GLL
}

Geomatics, Landmanagement and Landscape No. $1 \bullet 2020,53-61$

\section{THE IMPACT OF RASTER FILE OPTIMISATION ON THE PERFORMANCE OF A MAP APPLICATION}

\author{
Karol Król, Dariusz Zdonek
}

\begin{abstract}
Summary
Interactive data visualisations are popular and come in different forms, from static raster files to dynamic and complex proposals. The usability of the applications can be increased through the improvement of their technical attributes such as a reduced number of external components or image file compression. The objective of the paper is to analyse the correlation between raster compression and the performance of a map application. The research involved an application created specifically for this purpose. Raster compression and performance were measured using selected online tools. Raster compression has been demonstrated to enhance map application performance, although not all performance indicators improved.
\end{abstract}

\section{Keywords}

image compression • web services $\bullet$ geoinformatics $\bullet$ performance indicators $\bullet$ visual quality

\section{Introduction}

Websites and web applications are commonly used to present spatially referenced data. They are usually presented in tables (as text) or as graphic elements, infographics, charts, maps, or other visualisations [Król and Prus 2018]. Advanced, interactive data visualisations are usually created using frameworks or APIs. Complex dashboards or map services usually constitute independent applications or websites [Pispidikis and Dimopoulou 2015]. At the same time, wizards and generators are being developed and offered for less advanced, standardised website components. Interactive map applications are created using libraries such as jQuery or Leaflet as well [Sack and Roth 2017]. The differences between the applications include design, functionalities, usability, and performance. The usability of the applications can be improved by increased interaction potential as well as amended technical attributes, including the performance; also, through minification [Skolka et al. 2019] or raster image file compression [Uthayakumar et al. 2018].

The objective of the paper is to analyse the relationship between raster compression and the performance of a map application. The research question is: to what extent can 
raster compression affect map application performance? The answer can provide arguments for the most effective method of compressing image files.

A model map application with raster maps was developed to answer the research question. Two versions of the application were prepared, basic and compressed. Raster compression was performed using selected online applications. The performance of both versions was then tested. The results were juxtaposed.

\section{Image size matters}

By image data, we actually mean the representation of real-life graphics in digital form, which can be processed by conventional computers. The word 'digital' means in this case that the data in this representation are discrete. For example, the display area of a conventional computer screen consists of a large number of small discrete units called pixels [Pu 2006, p. 189].

Two characteristics of image data are quantity and quality. The first characteristic of images is related to the massive amount of data involved in almost every application. Images are stored in files, which tend to be much bigger in size compared to text files. For text files in ASCII, a book of a million words may occupy about $5 \mathrm{MB}$. In contrast, one image file can easily be even a million times bigger. The second characteristic of images is that the quality of an image depends not only on the image data but also on the display device and the perception of the human visual system [Pu 2006].

The impact of image file compression on a map application performance

Despite dynamic technological advances, the demand for mass storage capacity and data transmission bandwidth still cannot be satisfied with available technology. The reason is the growing amount of data. Uncompressed data require much more storage and bandwidth. It is particularly true for such multimedia as audio, video, or images [Sudhakar et al. 2005].

The explosive growth of data in the digital world calls for efficient technology that would enable data storage and transmission. Due to limited resources, data compression technologies are proposed to minimize the size of stored or communicated data [Uthayakumar et al. 2018].

The digital image is stored on the medium as an image file. The file format depends on the intended use of the image, among other things. A raster image file can be saved in one of many available formats. The most popular ones are JPG, BMP, TIF, or PNG [Król and Bitner 2019]. The performance of a map application depends on such factors as the device it is viewed on, server performance, or the Internet connection [Król 2018]. Still, the dynamics of loading of image files depends mostly on their size, which can be optimised through data compression. Compression is the art of representing information in a compact form rather than its original or uncompressed form [ $\mathrm{Pu} 2006]$.

There are many data compression techniques. They can be categorised as lossless and lossy compression methods [Uthayakumar et al. 2018]. Image compression 
algorithms can be divided into first-generation and second-generation algorithms [Chew et al. 2008]. In the case of lossless compression, transformed data are identical to the source dataset. Lossless algorithms are used for documents whose quality is of particular importance, such as medical images or images that will be processed further [Ramya and Pushpa 2016]. Still, it is lossy algorithms that are most commonly used. Lossy compression does not allow for the full restoration of source data. This is why it is also referred to as irreversible compression.

Test results are expressed using various attributes. Performance represents how fast a service request can be completed. This attribute is related to values measured by testing tools, the response time, and latency. Performance belongs among the Quality of Service attributes. Performance testing itself is part of an issue which includes tests such as acceptance/qualification testing, installation testing, alpha and beta testing, reliability achievement and evaluation, regression testing, stress testing, recovery testing, configuration testing and usability testing [Cibulka 2013].

\section{Selected uses of map applications for rural areas}

Web applications streamline information flow and communications between local government units and residents. Examples of such solutions are online zoning plans (Fig. 1a) or so-called addressing systems (Fig. 1b). Map applications are also used in various ways to present tourist qualities of rural areas, forms of environment protection, administrative divisions, municipal list of monuments, or road maps. The applications differ in design. Raster images and vector layers are used equally often [Król and Bitner 2019].

a)

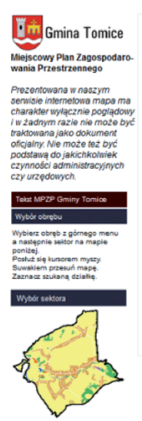

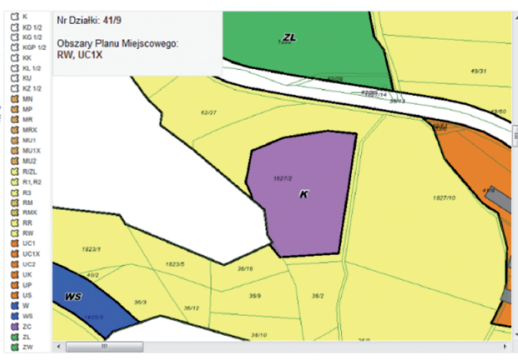

b)

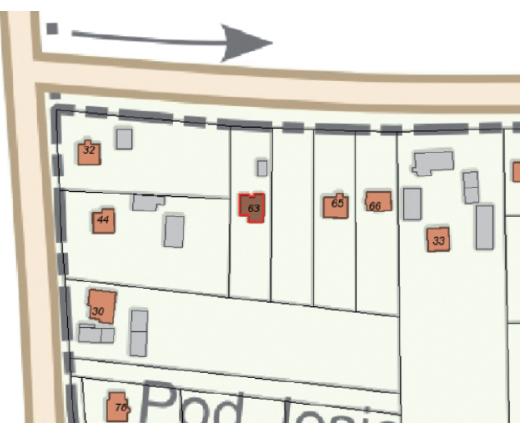

Source: original projects

Fig. 1. Map applications: an online zoning plan (https://tomice.pl/mpzp/) (1a) and a so-called addressing system (http://homeproject.pl/kozierow/) (1b)

Also interactive thematic maps with a specific topic are increasingly numerous. They can be produced by both local government units and by users as grassroots projects [Goodchild and Li 2012]. Ad-hoc publications can provide for 'momentary' needs such 
as public participation [Nummi and Tzoulas 2015], online voting on projects under participatory budgeting or variants in public projects.

\section{Materials and methods}

The research involved a map application explicitly created for this purpose. The application consisted of scripts (jQuery JavaScript), an HTML hypertext document, cascade style sheets CSS, and five image files (Fig. 2a). The application offered a general map of the municipality of Wadowice (Małopolska Region, Poland). The presented infrastructure was accompanied by a key, navigation menu, and a zoom feature [Król 2019]. The image files featured various resolutions and were superimposed on one another (Fig. 2b). This approach simulated zooming the map.

a)

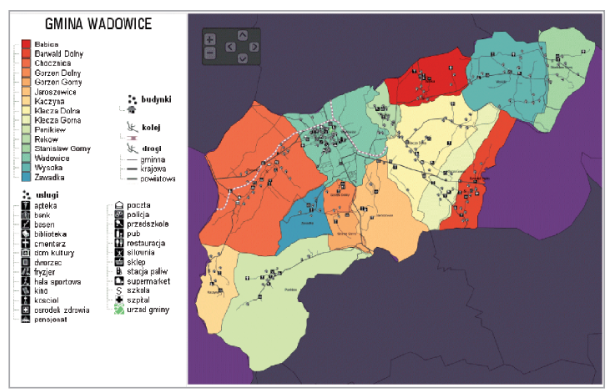

Source: Authors' own study

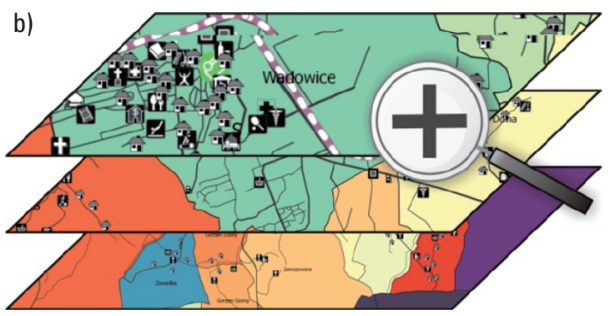

Fig. 2. An interactive general map of the municipality of Wadowice (Małopolska Region, Poland) (http://www.homeproject.pl/wadowice/) (2a) and simulated map zooming (2b)

The source vector map with the administrative subdivision of the municipality of Wadowice, the road network, developments, and services was created in QGIS. It was then converted into a PNG raster $5367 \times 4784$ px. The application was created using the MouseWheel Extension jQuery Plugin [Aaron 2019] and MapBox Zoomable jQuery Map Plugin [Abel 2019]. The scripts produce interactive maps that can be navigated with a mouse from multiple image files.

The user can view the administrative boundaries and subdivision of the municipality of Wadowice, situation of developments, road infrastructure, and service points. Note that such kind of a map is for illustrative purposes only and must not be considered an official document. It must not be used for any administrative or official purposes.

\section{Data compression tools and performance indicators}

Raster compression was performed using two applications, TinyPNG and Compressor. Performance testing was conducted independently for applications before and after raster compression. The performance was measured using two test applications (Table 1). 
Table 1. Online applications used in the research

\begin{tabular}{|l|l|l|l|}
\hline \multicolumn{1}{|c|}{ Analytical tool } & \multicolumn{1}{|c|}{ Website } & \multicolumn{1}{c|}{ Application } & \multicolumn{1}{c|}{$\begin{array}{c}\text { Measurement unit } \\
\text { (if applicable) }\end{array}$} \\
\hline TinyPNG & tinypng.com & PNG and JPEG compression & N/A \\
\hline Compressor & compressor.io & $\begin{array}{l}\text { Online tool for reducing the } \\
\text { size of images and photos }\end{array}$ & N/A \\
\hline GiftOfSpeed & giftofspeed.com & Website speed test & $\begin{array}{l}\text { - Fully Loaded Time } \\
\text { - Optimisation Score }\end{array}$ \\
\hline $\begin{array}{l}\text { Cloudinary Image } \\
\text { Analysis Tool }\end{array}$ & $\begin{array}{l}\text { webspeedtest. } \\
\text { cloudinary.com }\end{array}$ & Website speed test & $\begin{array}{l}\text { - Page Image Score } \\
\text { Potential Compressed } \\
\text { Weight }\end{array}$ \\
\hline
\end{tabular}

Source: Author's own study

The performance assessment involved four indicators, including Fully Loaded Time (FLT) and Optimisation Score (OS). The OS is a synthetic, aggregate measure - accumulation of the scores of all performance metrics $(0 / 100=$ worst, $100 / 100=$ best $)$. The Potential Compressed Weight (\%) reflects the degree of image file compression: the higher its value, the better (as long as the visual quality is unaffected). A PCW of 100\% means a 'permanently compressed' file (according to the Cloudinary Image Analysis Tool). The Page Image Score (PIS) is a synthetic measure of performance expressed as a letter (for example B = Good, $\mathrm{C}=$ Mediocre). The value of the PIS depends on the degree of image file optimisation.

\section{Results}

The basic version of the map application weighed less than $5 \mathrm{MB}$. TinyPNG reduced its total size by a little over $40 \%$ (Table 2). Compressor proved to be more effective with an approximate $60 \%$ reduction in weight. The decisive factor was the compression of the raster with the largest resolution $(5367 \times 4784$ pixels $)$, which was impossible with TinyPNG.

Table 2. The size of the map application before and after compression of raster files

\begin{tabular}{|l|c|c|c|}
\hline \multirow{2}{*}{ Map application attributes } & \multirow{2}{*}{$\begin{array}{c}\text { Map application before } \\
\text { compression of image files }\end{array}$} & \multicolumn{2}{c|}{$\begin{array}{c}\text { Map application after } \\
\text { compression of image files }\end{array}$} \\
\cline { 3 - 4 } & & TinyPNG & Compressor \\
\hline Raster map size (MB) & 4.84 & 2.76 & 1.86 \\
\hline Total map application size (MB) & 4.89 & 2.82 & 1.92 \\
\hline Total size (\%) & 100 & 57.7 & 39.3 \\
\hline
\end{tabular}

Source: Author's own study 
The data compression affected the performance of the application despite its failure to improve all performance indicators. Significant changes were noted for the Fully Loaded Time. The compression of the image files reduced the map application browser window loading time by almost 0.4 seconds (Table 3). The Potential Compressed Weight increased as well due to higher compression of the image files. There was still room for more compression, however.

Table 3. Performance results before and after image file compression

\begin{tabular}{|c|c|c|c|c|c|c|}
\hline \multirow{3}{*}{ Map application attributes } & \multirow{2}{*}{\multicolumn{2}{|c|}{$\begin{array}{l}\text { Map application before } \\
\text { compression of image files }\end{array}$}} & \multicolumn{4}{|c|}{$\begin{array}{l}\text { Map application after } \\
\text { compression of image files }\end{array}$} \\
\hline & & & \multicolumn{2}{|c|}{ TinyPNG } & \multicolumn{2}{|c|}{ Compressor } \\
\hline & G & $\mathrm{C}$ & G & $\mathrm{C}$ & G & $\mathrm{C}$ \\
\hline Fully Loaded Time (s) & 1.8 & N/A & 1.69 & N/A & 1.44 & N/A \\
\hline Optimisation Score & 68 & N/A & 68 & $\mathrm{~N} / \mathrm{A}$ & 68 & N/A \\
\hline Page Image Score & $\mathrm{N} / \mathrm{A}$ & B & $\mathrm{N} / \mathrm{A}$ & B & N/A & B \\
\hline Potential Compressed Weight (\%) & N/A & 23.2 & N/A & 69.9 & $\mathrm{~N} / \mathrm{A}$ & 76.3 \\
\hline
\end{tabular}

G - GiftOfSpeed (test location: New York, USA), C - Cloudinary

Source: Author's own study

The compression of the image files did not improve the Optimisation Score and Page Image Score. It could be due to the configuration of the test applications and the nature of the indicators, or the attributes considered for scoring. The performance improvement was not sufficient for a better PIS score.

\section{Discussion}

Image compression research aims at reducing the number of bits needed to represent an image by removing the spatial and spectral redundancies to the highest possible extent. In many different fields, digitised images are replacing conventional analogue images such as photographs or x-rays [Sudhakar et al. 2005].

Today, data compression techniques are essential in most real-time applications like satellite imagery, Geographical Information Systems (GIS), graphics, or Wireless Sensor Networks (WSN). Though the quality of data is tremendously increased by the development of recent technologies, it eventually increases the size of the data. For example, a moderate size colour image of $512 \times 512$ pixels requires about $0.75 \mathrm{MB}$ of storage space. A remote sensing image of $8192 \times 4096$ pixels requires about $96 \mathrm{MB}$ of disk storage. The reduction of file size facilitates storing more information in the same storage space with lesser transmission time. So, without data compression, it is challenging and sometimes impossible to store or communicate a huge amount of data files [Uthayakumar et al. 2018]. 
According to experts, it will be a priority of the coming years to ensure good performance of websites and web applications. A particular design focus should, therefore, be the performance. It hinges on such factors as the size of scripts and image files, their source (internal or external resources), the number of components, and data server configuration [Król and Bitner 2019].

Website performance may be decisive for its effectiveness (target conversion). Studies have shown that $80 \%$ of the time the user spends waiting for the site to load is used for downloading all its components, including image files and scripts [Lofgren 2019]. A mere one-second delay in the page render time pushes customer satisfaction down $16 \%$ and a page loading delay of 0.1 seconds can reduce target conversion by $7 \%$ [Chaffey and Patron 2012].

Fast-loading websites generate lower maintenance costs; they are viewed more readily and for a longer time. Even a half-second delay affects user activity [Singhal and Cutts 2010]. According to studies, users expect immediate hypertext system reaction below one second. Every other user becomes impatient when a page takes more than two seconds to load and $64 \%$ of mobile users expect websites to load under four seconds [Lofgren 2019]. A website, which takes 10 seconds and more to load may lose even $45 \%$ of the views and have a $135 \%$ higher bounce rate. As many as half of all mobile device users would leave a page that loads longer than three seconds. Moreover, studies have shown that an average user perceives the waiting time to be $15 \%$ longer than it actually is.

\section{Conclusions}

The MouseWheel Extension jQuery Plugin [Aaron 2019] and MapBox Zoomable jQuery Map Plugin [Abel 2019] help create web applications in a partially automated manner. Once prepared, components can present any raster file.

It is worth testing several compression tools when optimising image files. They may turn out to perform differently and leave room for more file optimisation.

Raster compression may affect map application performance significantly. Still, the optimisation of the size of image files should be done reasonably. Excessive focus on byte reduction may deteriorate the visual quality of image files or even render them useless. This, in turn, may lead to undesirable effects such as an increased bounce rate due to poor usability of the map application.

Funded with a subsidy of the Ministry of Science and Higher Education for the University of Agriculture in Kraków for 2020.

\section{References}

Aaron B. 2019. MouseWheel Extension jQuery Plugin. Version: 3.0.2. Dallas/Fort Worth. Texas USA. MIT License. http://brandonaaron.net [accessed: 24 January 2020].

Abel M. 2019. Mapbox: Zoomable jQuery Map Plugin. Wayfarer Web Services. Asheville, NC USA. MIT License. http://wayfarerweb.com/jquery/plugins/ [accessed: 24 January 2020]. 
Chaffey D., Patron M. 2012. From web analytics to digital marketing optimization: Increasing the commercial value of digital analytics. Journal of Direct, Data and Digital Marketing Practice, 14(1), 30-45. https://doi.org/10.1057/dddmp.2012.20

Chew L.W., Ang L.M., Seng K.P. 2008. Survey of image compression algorithms in wireless sensor networks. 2008 International Symposium on Information Technology, 4, 1-9. IEEE. https://doi.org/10.1109/ITSIM.2008.4631875

Cibulka D. 2013. Performance testing of web map services to three dimensions - x, y, scale. Slovak Journal of Civil Engineering, 21(1), 31-36. https://doi.org/10.2478/sjce-2013-0005

Goodchild M.F., Li L. 2012. Assuring the quality of volunteered geographic information. Spatial Statistics, 1, 110-120. https://doi.org/10.1016/j.spasta.2012.03.002

Król K. 2018. Performance threshold of the interactive raster map presentation - as illustrated with the example of the jQuery Java Script component. Geographic Information Systems Conference and Exhibition "GIS Odyssey", 321-327. http://bit.ly/GIS-ODYSSEY-2018 [accessed: 24 January 2020].

Król K. 2019. Zoomlens - graphic form of data presentation on a web map, comparison of chosen tool and usage examples. Engineering for Rural Development, 18, 1641-1648. https:// doi.org/10.22616/ERDev2019.18.N002

Król K., Bitner A. 2019. Impact of raster compression on the performance of a map application. Geomatics, Landmanagement and Landscape (GLL), 3, 41-51. http://dx.doi.org/10.15576/GLL/2019.3.41

Król K., Prus B. 2018. Application of interactive charts in the evaluation of socio-economic development of regions. The case of Poland. Acta Sci. Pol., ser. Formatio Circumiectus, 17(3), 141-151. https://doi.org/10.15576/ASP.FC/2018.17.3.141

Lofgren L. 2019. Website Speed Guide. QuickSprout. https://www.quicksprout.com/websitespeed/ [accessed: 24 January 2020].

Nummi P., Tzoulas T. 2015. Engaging citizens in cultural planning with a web map survey. Culture and Local Governance, 5(1-2), 1-13. https://doi.org/10.18192/clg-cgl.v5i1-2.1470

Pispidikis I., Dimopoulou E. 2015. Web development of spatial content management system through the use of free and open-source technologies. Case study in rural areas. Journal of Geographic Information System, 7(5), 527-540. https://doi.org/10.4236/jgis.2015.75042

Pu I.M. 2006. Fundamental Data Compression. Elsevier, Butterworth-Heinemann, Britain. https://doi.org/10.1016/B978-0-7506-6310-6.X5000-4

Ramya K.A., Pushpa M. 2016. A survey on lossless and lossy data compression methods. International Journal of Computer Science and Engineering Communications, 4(1), 1277-1280. https://doi.org/10.7910/DVN/5VL6XP

Sack C.M., Roth R.E. 2017. Design and evaluation of an Open Web Platform cartography lab curriculum. Journal of Geography in Higher Education, 41(1), 1-23. https://doi.org/10.108 0/03098265.2016.1241987

Singhal A., Cutts M. 2010. Using site speed in web search ranking. Google Webmaster Central Blog. https://goo.gl/sVusvY [accessed: 24 January 2020].

Skolka P., Staicu C.-A., Pradel M. 2019. Anything to Hide? Studying Minified and Obfuscated Code in the Web. Proceedings of the 2019 World Wide Web Conference (WWW '19), May 13-17, 2019, San Francisco, CA, USA, eds. J.B. Sartor, Th. D'Hondt, W. De Meuter. ACM, New York, NY, USA. https://doi.org/10.1145/3308558.3313752

Sudhakar R., Karthiga R., Jayaraman S. 2005. Image compression using coding of wavelet coefficients - a survey. ICGST-GVIP Journal, 5(6), 25-38.

Uthayakumar J., Vengattaraman T., Dhavachelvan P. 2018. A survey on data compression techniques: From the perspective of data quality, coding schemes, data type and applica- 
tions. Journal of King Saud University - Computer and Information Sciences. https://doi. org/10.1016/j.jksuci.2018.05.006

Dr inż. Karol Król

Uniwersytet Rolniczy w Krakowie

Katedra Gospodarki Przestrzennej i Architektury Krajobrazu

al. Mickiewicza 24/28, 30-059 Kraków

e-mail:k.krol@onet.com.pl

website: http://homeproject.pl

ORCID: https://orcid.org/0000-0003-0534-8471

Dr inż. Dariusz Zdonek

Politechnika Ślaska w Gliwicach

Wydział Organizacji i Zarządzania

Katedra Ekonomii i Informatyki

ul. Roosevelta 26, 41-800 Zabrze

e-mail: dariusz.zdonek@polsl.pl

ORCID: https://orcid.org/0000-0002-6190-9643 